\title{
Using the Negative Exponential Model to Describe Changes in Risk of Smoking-Related Diseases following Changes in Exposure to Tobacco
}

\author{
Peter N. Lee, John Hamling, John Fry, and Barbara Forey \\ P N Lee Statistics and Computing Ltd., 17 Cedar Road, Sutton, Surrey SM2 5DA, UK \\ Correspondence should be addressed to Peter N. Lee; peterlee@pnlee.co.uk
}

Received 13 April 2015; Accepted 13 July 2015

Academic Editor: Jeanine M. Buchanich

Copyright (C) 2015 Peter N. Lee et al. This is an open access article distributed under the Creative Commons Attribution License, which permits unrestricted use, distribution, and reproduction in any medium, provided the original work is properly cited.

Recently published analyses for four smoking-related diseases show that the declining excess relative risk by time quit is well fitted by the negative exponential model. These analyses estimated the half-life of this excess, that is, the time after quitting when the excess relative risk reaches half that for continuing smokers. We describe extensions of the simple model. One quantifies the decline following an exposure reduction. We show that this extension satisfactorily predicts results from studies investigating the effect of reducing cigarette consumption. It may also be relevant to exposure reductions following product-switching. Another extension predicts changes in excess relative risk occurring following multiple exposure changes over time. Suitable published epidemiological data are unavailable to test this, and we recommend its validity to be investigated using large studies with data recorded on smoking habits at multiple time points in life. The basic formulae described assume that the excess relative risk for a continuing smoker is linearly related to exposure and that the half-life is invariant of age. We describe model adaptations to allow for nonlinear doseresponse and for age-dependence of the half-life. The negative exponential model, though relatively simple, appears to have many potential uses in epidemiological research for summarizing variations in risk with exposure changes.

\section{Introduction}

A huge literature relates smoking to the risk of various major diseases. Although most of the evidence concerns comparison of risk in never and current smokers, many studies show that quitters have intermediate risks. Until now, few researchers have attempted formal modelling of the time pattern of the decline in relative risk (RR) following quitting $[1,2]$ and then only based on data from individual studies. Recently, however, publications on ischaemic heart disease (IHD) [3], lung cancer [4], chronic obstructive pulmonary disease (COPD) [5], and stroke [6] have fitted the negative exponential model (NEM) to multiple data sets to describe quantitatively the pattern of decline in RR with increasing time quit.

While these publications [3-6] provide important information on the benefits of quitting smoking, they are limited by not more generally considering how RR changes with variation in exposure to tobacco products. Thus, apart from quitting, smokers may change the amount they smoke, switch to a reduced exposure product, or may restart smoking having previously quit. Indeed, their level of exposure may change a number of times during their lifetime, and it would be useful to be able to model how RR varies over time for complex smoking histories. Not only would such a model allow a more comprehensive description of the risks associated with differing lifetime patterns of smoking, it may also be useful when attempting to predict the health impacts of novel products.

This paper describes extensions to the NEM to allow modelling of complex smoking histories. Section 2 gives a formal definition of the NEM; Section 3 then briefly summarizes material from the published papers on quitting [36] concerning the methodology used, the goodness-of-fit of the data for the different diseases studied, and evidence on between-study heterogeneity. Section 4 describes a first 
extension to the NEM which applies to reducing cigarette consumption or switching to a reduced exposure product. A recent review [7] provides estimates of the reduction in lung cancer risk following a reduction in cigarette consumption, and it is shown that the NEM extension fits these data well. Section 5 describes a further extension of the NEM to allow for multiple exposure changes and illustrates it by some examples. No published epidemiological data are available to verify this, and we suggest that its validity might be tested using large data sets which have recorded changes in smoking habits at multiple time points. The methods described up to this point assume that exposure is linearly related to the excess relative risk $(E R=R R-1)$ and that the rate of its decline with time is invariant of age. Section 6 describes adaptations of the NEM which allow for nonlinearity of the doseresponse and for the rate of decline in ER to vary with age.

The methods described and justified here give fuller detail than those summarized recently by Weitkunat et al. [8] when outlining a novel approach to assess the population health impact of introducing a modified risk tobacco product (MRTP). In that approach two sets of simulated individual smoking histories are compared, one scenario being derived on the assumption that the MRTP is introduced into the population and the other scenario derived assuming that it is not. The histories are derived from assumptions concerning the extent to which smokers will start smoking the two types of product (conventional cigarettes or MRTPs), will switch from one product to another, or will quit. The RR of the major smoking-related diseases (compared to never smokers) is then estimated for each individual's smoking history using the formulae described here, and average risks over individuals for each scenario are then used to estimate the reduction in deaths attributable to the assumed level of adoption of the MRTP.

\section{The Negative Exponential Model}

The NEM predicts that the smoking-associated ER declines with time quit, so that if $\operatorname{ER}_{S}(a)$ is the ER in current smokers compared to never smokers, where $a$ is age in years, then $\operatorname{ER}_{Q}(a, t)$, the ER in quitters of the same age, $t$ years after quitting, is given by

$$
\operatorname{ER}_{\mathrm{Q}}(a, t)=\mathrm{ER}_{S}(a) \exp \left(-\frac{t L}{H}\right)
$$

where $L=\log _{e} 2$ and $H$ is the "half-life," that is, the time since quitting when the ER declines to half that associated with continuing smoking.

\section{Quitting Smoking}

Studies which relate risk to time quit typically present RRs and $95 \%$ confidence intervals (CIs), relative to never smokers, for current smokers and for quitters by grouped period of time quit. Some studies present RRs and CIs for never smokers and quitters, expressed relative to current smokers. Typically, the RRs are adjusted for potential confounding variables. As described in detail elsewhere [3], fitting the
NEM requires a pseudotable to be estimated (using the method of Hamling et al. [9]). This pseudotable consists of numbers of subjects subdivided by smoking habit and disease status which correspond to the observed RRs and 95\% CIs. For prospective studies the numbers are of cases and at risk, and for case-control studies they are of cases and controls. Using these data and estimates of $t$, the midpoint time quit (taken to be zero for current smokers and infinite for never smokers) and maximum likelihood methods then allow fitting of the model. For prospective studies, the model is

$$
P_{j}=A+B \exp \left(-C t_{j}\right),
$$

where $P_{j}$ is the absolute risk of disease at time quit $t_{j}$ and $A$, $B$, and $C$ are parameters to be estimated. Here $j$ references smoking group (current smokers, quitters by time quit, or never smokers), $A$ is the absolute risk in never smokers, and $A+B$ is the absolute risk in current smokers. $C$ is equal to $L / H$. For case-control studies, the model differs as follows:

$$
P_{j}^{*}=1+B^{*} \exp \left(-C t_{j}\right)
$$

Here $P_{j}^{*}$ is the RR (versus never smokers, estimated by the odds ratio) not the absolute risk $\left(P_{j}\right)$, and $B^{*}$ is the ER, rather than the increase in absolute risk $(B)$, in current smokers. The interpretation of $C$ is the same as for prospective studies.

Lee et al. [3] describe methods for testing goodnessof-fit, carrying out meta-analysis of estimates of $H$, and testing heterogeneity. They also describe sensitivity analyses which attempt to account for "reverse causation" (short-term quitters having an increased risk as quitting can be prompted by symptoms from undiagnosed disease), either by omitting short-term quitters or by reclassifying them to be current smokers. The methodology has recently been applied to all available data sets for four major smoking-related diseases. The analysis for IHD [3] was based on 41 independent blocks of RRs from 23 studies [10-32], that for COPD [5] on 14 blocks from 11 studies [23, 33-42], and that for stroke [6] on 22 blocks from 13 studies $[15,19,20,23,25,37,38,43-48]$. The analysis for lung cancer [4] was based on the most data, involving 106 blocks of RRs from 85 studies, 30 in the USA or Canada [23, 45, 49-76], 25 in Europe [10, 13, 30, 34, 77-97], and 30 from other or multiple countries [19, 37, 38, 72, 98-122]. (Note that one publication [38] provided separate data for two different Australian studies, while another [72] provided separate data for a US and a Japanese study.) Based on the combined results, various conclusions can be made, which are summarized below.

3.1. Failure to Fit. The method may fail to converge to a valid solution $(H>0)$ or may converge to a solution with a huge variance, when a decline in risk following quitting is not clearly evident. This most often occurs when the current smoker RR is not or only minimally elevated. Failure (leading to exclusion from further analysis) occurred for none of 106 lung cancer data sets, one of 41 IHD sets, where the current smoker RR was 1.0, and one of 14 COPD sets, where no risk decline following quitting was evident. Failure often occurred 
for stroke, where current smoker RRs were below 1.4. Here, our meta-analysis used only those 11 (of 22) data sets which showed a stronger relationship with smoking.

3.2. Goodness-of-Fit. Where convergence did occur, goodness-of-fit, as assessed by comparison of observed and fitted numbers, was adequate for every COPD and stroke data set and for nearly all IHD sets, except where the decline in risk was clearly nonmonotonic. For lung cancer, model fit was poor when reverse causation was ignored but was much improved in sensitivity analyses omitting short-term quitters or counting them as current smokers. However, some misfit remained, seemingly resulting from odd data patterns in individual studies rather than from any systematic misfit.

3.3. Estimates of Half-Life. Meta-analysis $H$ estimates (years) were larger for COPD, 13.32 (95\% CI 11.86-14.96), and lung cancer, 9.93 (9.31-10.60), than for IHD, 4.40 (3.26-5.95), or stroke, 4.78 (2.17-10.50). It has been shown more recently [123] that the half-life is somewhat greater for adenocarcinoma than for squamous cell carcinoma of the lung, with the ratio of the Hs for the two cell types estimated as 1.32 (1.201.46).

These estimates provide more precise information on the pattern of the decline in ER following quitting than that found in various authoritative reviews, for example, [15, 124-126]. Thus, for example, the International Agency on Research and Cancer (IARC) [126] notes for IHD that, though the data were heterogeneous, "the body of evidence points toward the risk of CHD asymptotically approaching the risk of never smokers." While imprecise, this conclusion seems correct. The same cannot be said of an earlier report, by the US Surgeon-General [15], which stated that "the excess risk of CHD caused by smoking is reduced by about half after 1 year of smoking abstinence and then declines gradually. After 15 years of abstinence, the risk of CHD is similar to that of persons who have never smoked." Here the indicated decline in ER following quitting is much more rapid than indicated by the overall data currently available.

For lung cancer, the US Surgeon-General [15] stated that "after 10 years of abstinence, the risk of lung cancer is about $30-50 \%$ of the risk for continuing smokers; with further abstinence, the risk continues to decline." While not incorrect, the statement does not fully quantify the decline in ER with time.

As far as we are aware, there have been no attempts, for any of the four diseases considered, to formally quantify the shape of the decline in risk following quitting based on all the available epidemiological evidence.

3.4. Sensitivity Analyses. Although improving the fit, the sensitivity analyses had little effect on the meta-analysis estimates of $H$. This was unsurprising as, for each data set, the estimated $H$ was usually close to where the ratio of ERs in quitters and continuing smokers reduced to below 50\%. This would occur longer after quitting than when the short-term increases were seen.
3.5. Heterogeneity. Heterogeneity between individual $H$ estimates for a disease was assessed by likelihood-ratio tests. Significant $(p<0.05)$ heterogeneity was not seen for COPD but was seen for the other diseases, markedly so for IHD (where $H$ was estimated as $<2$ years for 10 of 40 data sets and as $>10$ years for 12) and for stroke. For lung cancer, $H$ was somewhat higher in males and in older populations. For IHD and stroke, the relationship of $H$ to age was also evident.

For all four diseases, the NEM was found to provide a simple method for summarizing quitting data, generally fitting it well. Misfits seen were mainly due to unusual results, which no plausible model could be expected to fit, rather than to any systematic misfits. However, the evidence of a greater $H$ in older populations, seen for three of the four diseases studied, suggests that some adaptation of the simple NEM may be required to allow for this. This is described later.

\section{Reducing Cigarette Consumption}

Quitting can be regarded as reducing the effective exposure from 1 to 0 units. The NEM can be extended, assuming that the ER is linearly related to exposure to estimate the ER, $\mathrm{ER}_{R}(a, t), t$ years after $a$ reduction in exposure from 1 to $F$ units, by

$$
\mathrm{ER}_{R}(a, t)=\mathrm{ER}_{S}(a)\left(F+(1-F) \exp \left(-\frac{t L}{H}\right)\right) .
$$

Here $t$ is the time since the reduction occurred. When $F=0$, formulae (1) and (4) are identical. Formula (4) can apply, not only to reducing cigarettes/day from, say, 25 to 15 $(F=0.6)$, but also to switching to a product with a reduced uptake of relevant smoke constituents. Note that the formula implies a linear dose-response relationship. Modification of the formula to allow for nonlinearity is discussed later (see Section 6.1).

A recent review on the effect on lung cancer risk of reducing amount smoked [7] summarized evidence from three prospective and three case-control studies which involved varying reductions in amount smoked over a varying time. Each study demonstrated a risk reduction, with a metaanalysis estimating the overall RR for reducers versus nonreducers as 0.81 (95\% CI 0.74-0.88).

To compare these results with the predictions of formula (4), data are required on the extent of reduction of consumption in the reducers, the length of follow-up since the reduction, and the average age of the subjects at the time of reduction. Such data were only available for the prospective studies, each of which involved two separate examinations when smoking habits were recorded and then a mortality follow-up period of 10 or more years. The study details and the observed and NEM predicted RRs are shown in Table 1.

Study 1 provided one RR estimate for sexes combined, study 2 provided one estimate per sex, and study 3 provided an estimate for males for different degrees of reduction. Each RR was adjusted for age and confounders. $F$, the ratio of consumption of post- to prereduction, varied from 0.17 to 0.50. $F$ values came from the source for studies 1 and 2 
TABLE 1: Summary of lung cancer results for reducing amount smoked from three prospective studies.

\begin{tabular}{|c|c|c|c|}
\hline Characteristic & Study 1 [148] & Study 2 [149] & Study 3 [150] \\
\hline Location & Denmark & Norway & Korea \\
\hline Sex & $\mathrm{M}$ and $\mathrm{F}$ combined & $\mathrm{M}, \mathrm{F}$ & $\mathrm{M}$ \\
\hline $\begin{array}{l}\text { Time between the two } \\
\text { examinations (years) }\end{array}$ & 5 to 10 & 3 to 13 & 2 \\
\hline $\begin{array}{l}\text { Follow-up period from } \\
\text { examination two (years) }\end{array}$ & 18 & 21.2 & 10.7 \\
\hline $\begin{array}{l}\text { Definition of a continuing } \\
\text { smoker ( } N \text { subjects) }\end{array}$ & $\begin{array}{l}\text { Heavy smoker (at least } 15 \\
\text { cigs/day) at each exam ( } N \\
7351)\end{array}$ & $\begin{array}{l}\text { Heavy smoker (at least } 15 \\
\text { cigs/day) at each exam }(N \\
4739 \mathrm{M}, 1831 \mathrm{~F})\end{array}$ & $\begin{array}{l}\text { At each exam subjects were } \\
\text { described as heavy }(20+, N \\
57730) \text {, moderate }(10-19, N \\
\text { 101347), or light }(<10 \\
\text { cigs/day, } N \text { 76754) }\end{array}$ \\
\hline \multirow{3}{*}{$\begin{array}{l}\text { Definition of a reducing } \\
\text { smoker ( } N \text { subjects) }\end{array}$} & \multirow[t]{3}{*}{$\begin{array}{l}\text { (1) Heavy smoker at first } \\
\text { exam reducing by at least } \\
50 \% \text { at the second exam }(N \\
832)\end{array}$} & $\begin{array}{l}\text { (2) As for study } 1 \text {, males ( } N \\
348)\end{array}$ & $\begin{array}{l}\text { (4) Heavy smoker at first } \\
\text { exam reducing to moderate } \\
\text { smoker at second exam }(N \\
15936)\end{array}$ \\
\hline & & $\begin{array}{l}\text { (3) As for study } 1 \text {, females } \\
\text { (N 127) }\end{array}$ & (5) Heavy to light ( $N$ 4293) \\
\hline & & & $\begin{array}{l}\text { (6) Moderate to light ( } N \\
\text { 19168) }\end{array}$ \\
\hline \multirow{3}{*}{$\begin{array}{l}\text { Ratio of average } \\
\text { consumption at the two } \\
\text { exams in reducers }(F)\end{array}$} & \multirow[t]{3}{*}{ (1) $8.5 / 20.2=0.42$} & (2) $9.7 / 22.9=0.42$ & (4) 0.50 \\
\hline & & (3) $8.6 / 19.5=0.44$ & (5) 0.17 \\
\hline & & & (6) 0.33 \\
\hline $\begin{array}{l}\text { Time from reduction to } \\
\text { end of follow-up (years) }\end{array}$ & 21.4 & 24.0 & 11.7 \\
\hline \multirow{3}{*}{ Cases in reducers } & \multirow[t]{3}{*}{ (1) 52} & (2) 10 & (4) 63 \\
\hline & & (3) 2 & (5) 95 \\
\hline & & & (6) 53 \\
\hline \multirow{3}{*}{$\begin{array}{l}\text { Average age at the time of } \\
\text { reduction (years) }(\bar{a})\end{array}$} & \multirow[t]{3}{*}{ (1) 49.0} & (2) 39.0 & (4) 42.6 \\
\hline & & (3) 38.2 & (5) 42.9 \\
\hline & & & (6) 42.4 \\
\hline \multirow{3}{*}{ Observed RRs $(95 \% \text { CIs })^{b}$} & \multirow[t]{3}{*}{ (1) $0.73(0.54-0.98)$} & (2) $0.71(0.36-1.39)$ & (4) $0.72(0.59-0.89)$ \\
\hline & & (3) $0.51(0.12-2.08)$ & (5) $0.63(0.46-0.86)$ \\
\hline & & & (6) $0.79(0.64-0.98)$ \\
\hline \multirow{3}{*}{ NEM predicted RRs } & \multirow[t]{3}{*}{ (1) 0.64} & (2) 0.60 & (4) 0.80 \\
\hline & & (3) 0.61 & (5) 0.67 \\
\hline & & & (6) 0.73 \\
\hline
\end{tabular}

${ }^{a}$ Estimated as the time of follow-up plus half the time between the two examinations.

${ }^{\mathrm{b}}$ Reducers relative to continuing smokers.

but for study 3 were based on assumed midpoints of 30, 15, and 5 cigs/day for the three categories used. The time from reduction to end of follow-up was estimated as length of follow-up plus half the time between examinations.

RRs were predicted using formula (4), as $F+(1-F) V$, where $V$ is a weighted mean value of $\exp (-t L / H)$ over the time from reduction to end of follow-up, the values being computed at 0.1 year intervals. Based on the DollPeto formula [127] the weighting factor was taken as $(\bar{a}-$ $22.5+t)^{4.5}, \bar{a}$ being the average age at time of reduction and $t$ being the time since the reduction occurred. This factor is necessary because the observed RR derives from cancers occurring at varying times after the reduction started, whereas formula (4) relates to the reduction in ER at a specific time. It also accounts for the absolute risk in continuing smokers rising with increasing age (or duration). $H$ was taken as 9.93, based on earlier work [4]. No account was taken of any survival differences between continuing smokers and reducers, likely to have relatively minor effect given the ages of the populations.

As seen in Table 1, the predicted RR is always near its observed value and lies well within its 95\% CI. For the six observed RRs, meta-analysis yields an estimate of 0.73 (95\% CI 0.64-0.82) with no heterogeneity. Using weights as for the observed data, the estimate based on the NEM predicted 
RRs, 0.71 (0.63-0.80), was similar. Although various assumptions and simplifications are involved, unavoidable without access to the full study data, and study 3 estimates are not independent (estimates 4 and 5 both involving comparisons with continuing heavy smokers), the predicted RR from formula (4) is clearly a good approximation to the observed value.

\section{Multiple Changes in Exposure}

Denoting the negative exponential function $\exp (-t L / H)$ by $N(t)$, formula (4) can be rewritten as

$$
\operatorname{ER}_{R}(a, t)=N(t) \operatorname{ER}_{S}(a)+(1-N(t)) F \mathrm{ER}_{S}(a) .
$$

More generally, for someone switching from exposure $F_{1}$ to $F_{2}$ units, the ER for the switcher, $\operatorname{ER}_{\mathrm{sw}}(a, t)$ can be expressed as

$$
\operatorname{ER}_{\mathrm{sW}}(a, t)=N(t) F_{1} \mathrm{ER}_{S}(a)+(1-N(t)) F_{2} \operatorname{ER}_{S}(a),
$$

where $t$ is the time since switch. Setting $F_{1}=1$ and $F_{2}=F$, the two formulae are clearly the same.

Figure 1 illustrates various patterns of observed $\mathrm{ER}_{S}$. The five lines in red relate to smokers of conventional cigarettes $(F=1, \mathrm{ER}=10)$ who, at the age of 40 , either continue to smoke conventional cigarettes, switch to differing MRTPs (with $F=0.75,0.50$, or 0.25$)$, or quit $(F=0)$. The five lines in blue relate to smokers of one type of MRTP $(F=0.5, \mathrm{ER}=$ 5 ) who, at the age of 40 , either continue to smoke the same product, switch to conventional cigarettes, switch to other modified risk products $(F=0.75,0.25)$, or quit $(F=0)$. $H$ is set as 10 throughout.

This formulation can be extended to allow for multiple periods of exposure. We first define the following:

$$
G+1 \text { : number of periods }(g=0,1, \ldots, G),
$$

$Z_{g}$ : the time of the $g$ th exposure change,

$F_{g}$ : the exposure in period $g$, with $F_{0}$ taken as zero,

$X(a)$ : the ER for a continuing smoker with $F=1$, at age $a$, the value being derived from epidemiological data,

$\operatorname{ER}\left(k, a, F_{1}, F_{2}, \ldots, F_{k}\right)$ : the ER in period $k$ at age $a$ for the given pattern of exposure. Note that ER is only defined for $a>Z_{k}$.

The method of estimation of $\operatorname{ER}\left(k, a, F_{1}, F_{2}, \ldots, F_{k}\right)$ is illustrated below for four switches $(G=4)$ working through the five periods in turn.

In period $0, \operatorname{ER}(0, a)$ is zero.

In period 1, the ERs are estimated by multiplying the exposure by $X(a)$. To allow calculation for later periods, this must be estimated for each later exposure. Thus, we have

$$
\begin{aligned}
& \operatorname{ER}\left(1, a, F_{1}\right)=F_{1} X(a), \\
& \operatorname{ER}\left(1, a, F_{2}\right)=F_{2} X(a), \\
& \operatorname{ER}\left(1, a, F_{3}\right)=F_{3} X(a), \\
& \operatorname{ER}\left(1, a, F_{4}\right)=F_{4} X(a) .
\end{aligned}
$$

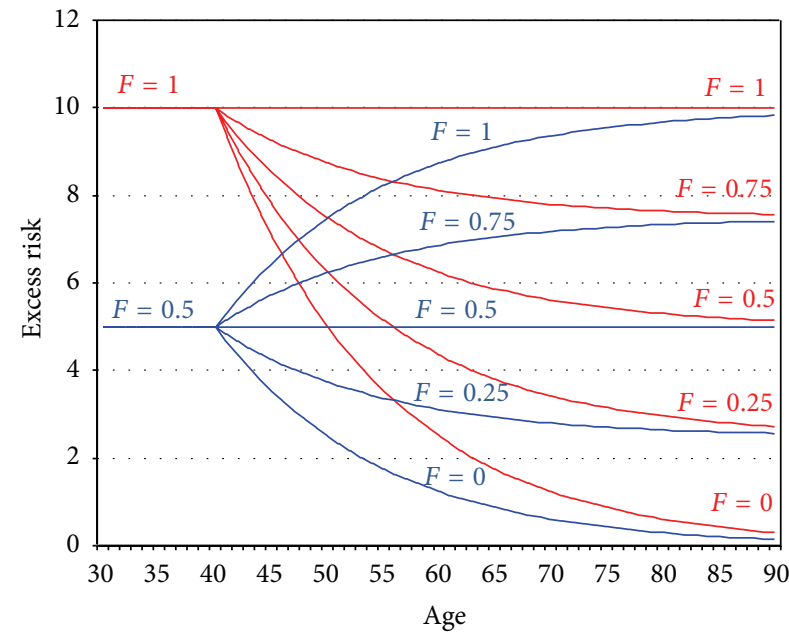

FIGURE 1: Excess risks predicted by the NEM for a single change in exposure. The red lines are NEM predicted ERs for smokers of conventional cigarettes $(F=1, \mathrm{ER}=10)$ who, at the age of 40 , either continue smoking these, switch to modified risk products $(F=0.75$, 0.50 , or 0.25$)$, or quit $(F=0)$. The blue lines are for smokers of modified products $(F=0.5, \mathrm{ER}=5)$ who, at the age of 40 , either continue smoking these, switch to conventional cigarettes or to other modified risk products $(F=0.75$ and 0.25$)$, or quit $(F=0)$. $H$ is set at 10 throughout.

In period 2, the ERs are calculated from period 1 ERs as follows:

$$
\begin{aligned}
\operatorname{ER}\left(2, a, F_{1}, F_{2}\right)= & N\left(a-Z_{2}\right) \operatorname{ER}\left(1, a, F_{1}\right) \\
& +\left(1-N\left(a-Z_{2}\right)\right) \operatorname{ER}\left(1, a, F_{2}\right), \\
\operatorname{ER}\left(2, a, F_{1}, F_{3}\right)= & N\left(a-Z_{2}\right) \operatorname{ER}\left(1, a, F_{1}\right) \\
& +\left(1-N\left(a-Z_{2}\right)\right) \operatorname{ER}\left(1, a, F_{3}\right), \\
\operatorname{ER}\left(2, a, F_{1}, F_{4}\right)= & N\left(a-Z_{2}\right) \operatorname{ER}\left(1, a, F_{1}\right) \\
& +\left(1-N\left(a-Z_{2}\right)\right) \operatorname{ER}\left(1, a, F_{4}\right) .
\end{aligned}
$$

In period 3, the ERs are calculated from period 2 ERs as follows:

$$
\begin{aligned}
\operatorname{ER}\left(3, a, F_{1}, F_{2}, F_{3}\right) \\
=N\left(a-Z_{3}\right) \operatorname{ER}\left(2, a, F_{1}, F_{2}\right) \\
\quad+\left(1-N\left(a-Z_{3}\right)\right) \operatorname{ER}\left(2, a, F_{1}, F_{3}\right), \\
\operatorname{ER}\left(3, a, F_{1}, F_{2}, F_{4}\right) \\
=N\left(a-Z_{3}\right) \operatorname{ER}\left(2, a, F_{1}, F_{3}\right) \\
\quad+\left(1-N\left(a-Z_{3}\right)\right) \operatorname{ER}\left(2, a, F_{1}, F_{4}\right) .
\end{aligned}
$$

Similarly in period 4 , we have

$$
\begin{aligned}
& \operatorname{ER}\left(4, a, F_{1}, F_{2}, F_{3}, F_{4}\right) \\
&= N\left(a-Z_{4}\right) \operatorname{ER}\left(3, a, F_{1}, F_{2}, F_{3}\right) \\
&+\left(1-N\left(a-Z_{4}\right)\right) \operatorname{ER}\left(3, a, F_{1}, F_{2}, F_{4}\right) .
\end{aligned}
$$




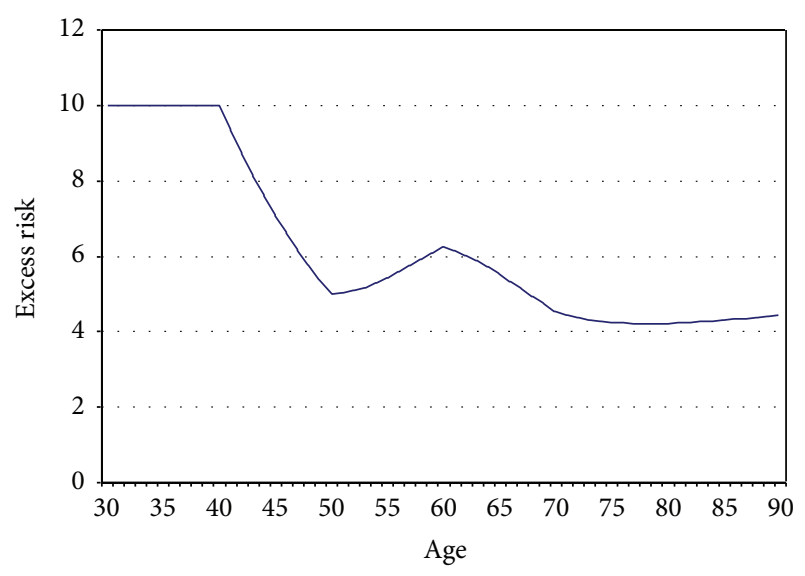

FIGURE 2: Excess risks predicted by the NEM for the first pattern of changes in smoking habit. NEM predicted ERs are shown for smokers $(F=1)$ who quit at the age of 40 , resume at the age of $50(F=1)$, quit again at the age of 60 , and then resume at a lower consumption at the age of $70(F=0.5)$. The ER is taken to be 10 for $F=1$ at the age of $40 . H$ is set at 10 years.

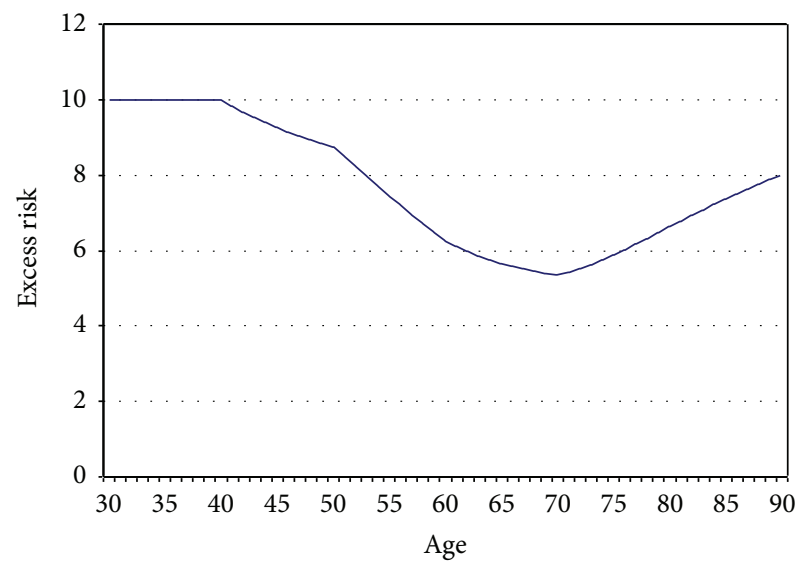

FIGURE 3: Excess risks predicted by the NEM for the second pattern of changes in smoking habit. NEM predicted ERs are shown for smokers $(F=1)$ who cut down slightly at the age of $40(F=0.75)$, cut down further at the age of $50(F=0.25)$, increase consumption at the age of $60(F=0.5)$, and then return to their original smoking habits at the age of $70(F=1)$. The ER is taken to be 10 for $F=1$ at the age of $40 . H$ is set at 10 years.

Thus the person of interest, with exposures $0, F_{1}, F_{2}$, $F_{3}$, and $F_{4}$, has the ERs in each period given by the first equation shown for each period. The other ERs are used only to calculate these.

Figures 2, 3, and 4 show illustrative results for three smoking patterns, each starting with smoking of conventional cigarettes $(F=1)$ up to the age of 40 when the ER is taken as 10 but involving differing patterns later. $H$ is set as 10 , as for Figure 1. Figure 2 concerns smokers who quit at the age of 40 , resume at the age of $50(F=1)$, quit again at the age of 60 , and resume at the age of $70(F=0.5)$. Figure 3 concerns smokers who reduce consumption slightly at the age of $40(F=0.75)$, further reduce consumption at the age of 50

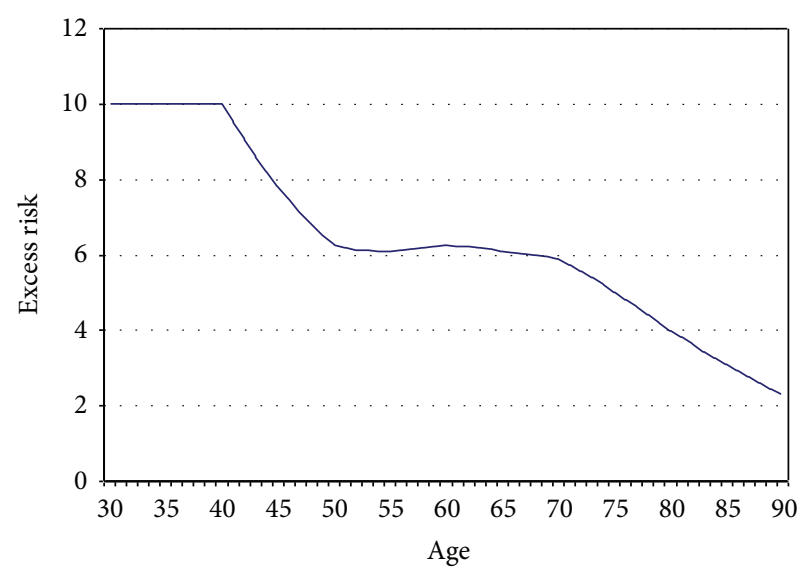

FIgURE 4: Excess risks predicted by the NEM for the third pattern of changes in smoking habit. NEM predicted ERs are shown for smokers $(F=1)$ who cut down markedly at the age of $40(F=$ $0.25)$, increase consumption at the age of $50(F=0.75)$, cut down consumption at the age of $60(F=0.5)$, and quit at the age of 70 . The ER is taken to be 10 for $F=1$ at the age of 40 . $H$ is set at 10 years.

$(F=0.25)$, increase consumption at the age of $60(F=0.5)$, and return to their original habits at the age of $70(F=1)$. Figure 4 concerns smokers who cut down markedly at the age of $40(F=0.25)$, increase consumption at the age of 50 $(F=0.75)$, reduce consumption at the age of $60(F=0.5)$, and then quit at the age of 70 .

Note that, as far as we are aware, there are no published epidemiological data available giving changes in risk following multiple periods of exposure which would allow formal comparisons to be made of observed risks and those predicted by the formulae given above.

\section{Modifications of the NEM}

6.1. Allowing for Variation in the Dose-Response Relationship. The methods described in Sections 4 and 5 assume that exposure is linearly related to the ER. Although recent doseresponse meta-analyses [128] show little upward curvature in the relationship between ER and the amount smoked per day, a nonlinear dose-response has been claimed, with Doll and Peto [127] suggesting that risk is proportional to the $($ cigs/day +6$)$ squared. $F$ can be adjusted to take account of nonlinearity, as illustrated below for the Doll and Peto example.

Thus, suppose that $F=1$ corresponds to 20 cigarettes/day, so the ER is proportional to $26^{2}-6^{2}=640$, where $26^{2}$ is the dose factor in the Doll/Peto formula for smokers and $6^{2}$ is that for nonsmokers. Adjusted $F$ values, $F^{*}$, are then calculated by $F^{*}=\left((20 F+6)^{2}-6^{2}\right) / 640$, so that multiplying the ER for $F=1$ by $F^{*}$ gives the quadratically interpolated curves. Thus unadjusted $F$ values of $0.75,0.5,0.25$, and 0.1 become adjusted $F^{*}$ values of $0.633,0.344,0.133$, and 0.044 .

6.2. Allowing for Variation in the Half-Life. As shown in Table 2 there is evidence that $H$ increases with age for lung 
TABLE 2: Variation in $H$ by age ${ }^{a}$ for four smoking-related diseases as estimated in four recent publications.

\begin{tabular}{|c|c|c|c|c|c|}
\hline \multirow{2}{*}{ Disease } & \multicolumn{5}{|c|}{ Estimates of $H(95 \% \mathrm{CI})$} \\
\hline & Age $<50$ & Age 50-59 & Age 60-69 & Age 70-79 & $p^{\mathrm{b}}$ \\
\hline IHD [3] & $\begin{array}{c}1.47 \\
(0.91-2.39)\end{array}$ & $\begin{array}{c}5.22 \\
(3.79-7.20)\end{array}$ & $\begin{array}{c}7.48 \\
(4.56-12.28)\end{array}$ & $\begin{array}{c}13.77 \\
(4.27-44.35)\end{array}$ & $<0.001$ \\
\hline Lung cancer [4] & $\begin{array}{c}6.98 \\
(5.98-8.16) \\
\end{array}$ & $\begin{array}{c}10.39 \\
(9.45-11.42)\end{array}$ & $\begin{array}{c}10.60 \\
(9.70-11.58)\end{array}$ & $\begin{array}{c}12.99 \\
(8.15-20.69)\end{array}$ & $<0.001$ \\
\hline COPD [5] & $\begin{array}{c}9.97 \\
(5.67-17.55) \\
\end{array}$ & $\begin{array}{c}14.18 \\
(12.35-16.28) \\
\end{array}$ & $\begin{array}{c}16.06 \\
(9.70-26.60)\end{array}$ & $\begin{array}{c}11.60 \\
(9.40-14.31)\end{array}$ & 0.22 \\
\hline Stroke [6] & $\begin{array}{c}1.98 \\
(0.41-9.65)\end{array}$ & $\begin{array}{c}3.47 \\
(0.79-15.19)\end{array}$ & $\begin{array}{c}7.71 \\
(2.12-27.97)\end{array}$ & $\begin{array}{c}17.74 \\
(1.46-215.7)\end{array}$ & 0.34 \\
\hline
\end{tabular}

${ }^{a}$ For prospective studies taken as age at baseline for IHD, COPD, and stroke but as age at midpoint of follow-up for lung cancer.

${ }^{\mathrm{b}}$ Heterogeneity between groups.

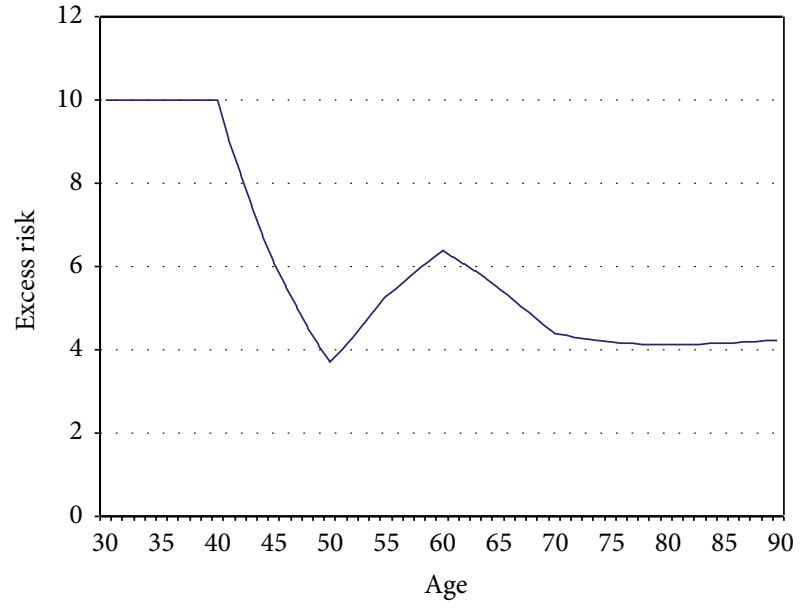

FIGURE 5: Excess risks predicted by the NEM for the first pattern of changes in smoking habit but allowing $H$ to vary with time. NEM predicted ERs are shown for smokers $(F=1)$ who quit at the age of 40 , resume at the age of $50(F=1)$, quit again at the age of 60 , and then resume at a lower consumption at the age of $70(F=0.5)$. The ER is taken to be 10 for $F=1$ at the age of 40 . Instead of setting $H$ as 10 years (as in Figure 2), $H$ is set at 7 years for ages $40-55,10$ years for ages $55-70$, and 14 years at older ages.

cancer [4], IHD [3] and stroke [6], although not for COPD [5]. A modification of the NEM allows for this. Thus, whereas when $H$ is invariant of age $N(t)$ is defined as $\exp (-t L / H)$, where $t$ is time since switch, for varying $H, N(t)$ is defined as the product of terms in $\exp \left(-t_{i} L / H_{i}\right)$, with time since switch divided into $r$ periods $(i=1, \ldots, r)$ where the half-life is $H_{i}$.

Figure 5 corresponds to Figure 2, showing predicted ERs for the first smoking pattern described above. Here instead of constant 10 years, $H$ is set at 7 years for ages $40-55$, at 10 years for ages 55-70, and then at 14 years. While the initial decline is greater in Figure 5 than in Figure 2, the predicted ER is very similar after the age of 70 .

\section{Discussion}

Based on substantial data for IHD [3] and lung cancer [4] and more limited data for COPD [5] and for stroke [6], the decline in ER following quitting has been shown to fit well the simplest NEM version (formula (1)). Using more limited data, the decline in lung cancer risk following reducing cigarette consumption can be fitted well by an extended form (formula (4)).

The further extension (formula (6)) allows estimation of ER following multiple exposure changes. All it requires are estimates of $H$, the ER for continued smoking $(F=1)$, and the exposures $(F)$ in each relevant period. The formula allows estimation of predicted risk patterns, not only for intermittent smoking periods and consumption changes, but also for changes in product smoked. Thus if conventional cigarette smoking has factor $F=1$, and a MRTP [129] reduces exposure to relevant smoke constituents by $80 \%, F$ would be set as 0.2. $F$ for dual users, using half conventional cigarettes and half MRTPs, could be set as $0.5(1+0.2)=0.6$. Given data on switching rates from conventional cigarettes to MRTP and the frequency of dual use, the NEM can then predict changes in risk for smoking-related diseases.

Validating formula (6) is problematic, since published suitable epidemiological data on risk changes following multiple exposure changes are lacking. It is likely that, in fact, large epidemiological data sets exist which have recorded data on the extent of smoking at three or more time points. Providing that there are sufficient numbers of subjects showing differing patterns of changing exposure, it would be valuable to test the accuracy of fit to the NEM.

Formula (6) is most simply employed with $F_{i}$ taken as proportional to the extent of exposure, thus implicitly assuming a linear dose-response relationship. In fact, recent extensive dose-response analyses for lung cancer [128] do not suggest marked nonlinearity, and the same seems true for COPD [130] and other smoking-related diseases [131, 132]. However, it is possible, as we describe, to adapt the NEM to allow for nonlinearity by using values of $F_{i}$ that reflect alternative relationships. It should be noted that observed dose-response relationships may not precisely reflect the truth because of inaccurate reporting of amount smoked. Though the assumption of linearity may not be correct, it certainly serves as a useful simple starting point for ER estimations.

Another assumption inherent in formula (6) is that $H$ is invariant of age. Available results (see Table 2) suggest 
that $H$ increases with age for lung cancer, IHD, and stroke, though not for COPD. There is therefore a case for using agedependent estimates of $H$, and we describe an adaptation of the NEM to allow for this. However, it may be difficult to obtain precise estimates. Those in Table 2 come from casecontrol and prospective studies. For case-control studies, age is when the cancer occurred, but for prospective studies it was taken as age at baseline (or for lung cancer, midpoint age of follow-up); such studies do not usually report risk by actual age.

Another issue is uncertainty in $H$, particularly for IHD and stroke, where substantial heterogeneity from different available data sets $[3,6]$ renders the overall estimate less reliable. This creates uncertainty in ER estimates resulting from varying exposure histories, which might be addressed by presenting estimates using alternative $H$ values (e.g., \pm 1 SE).

This paper does not attempt to further investigate the usefulness of the NEM by comparing its predictions with other models. There are two reasons for this. Firstly, the fit to more detailed models has only been studied for some of the diseases of interest. Second, for lung cancer, where various models have been tried, such as the multistage model (see e.g., $[1,133-143])$ or the two-stage clonal expansion model [144147], full comparisons of the predictions of the NEM and other models would be a major exercise, beyond the scope of this paper. We prefer, if possible, to test the goodness-offit of the NEM using available data sets. At the present time, we feel that the material presented suggests that the NEM is a valuable, simple tool meriting further investigation.

\section{Conclusion}

The NEM is a useful model with many applications to smoking and health data. The most general form not only allows a simple description of the time course of disease following quitting, but can predict changes in risk following single or multiple reductions or increases in exposure, whether resulting from changes in amount smoked or the type of product smoked, perhaps following switching to MRTPs.

\section{Disclosure}

Neither sponsor was involved in the planning, execution, or writing of the paper or the decision to submit it for publication.

\section{Disclaimer}

The opinions and conclusions of the authors are their own and do not necessarily reflect the position of Philip Morris Products S.A.

\section{Conflict of Interests}

Peter N. Lee, founder of P. N. Lee Statistics and Computing Ltd., is an independent consultant in statistics and an advisor in the fields of epidemiology and toxicology to a number of tobacco, pharmaceutical, and chemical companies. This includes Philip Morris Products S.A., the sponsor of this study. The other three authors are employees of P. N. Lee Statistics and Computing Ltd.

\section{Acknowledgments}

The authors thank Philip Morris Products S.A. that funded the work. They also thank Pauline Wassell, Diana Morris, and Yvonne Cooper for assistance in typing the various drafts of the paper and obtaining the relevant literature. The preparation of the paper and work on quitting smoking and multiple exposure changes was supported by Philip Morris Products S.A. The work on cigarette consumption reduction was supported by Altria Client Services Inc.

\section{References}

[1] C. C. Brown and K. C. Chu, "Use of multistage models to infer stage affected by carcinogenic exposure: example of lung cancer and cigarette smoking," Journal of Chronic Diseases, vol. 40, supplement 2, pp. 171S-179S, 1987.

[2] M. T. Halpern, B. W. Gillespie, and K. E. Warner, "Patterns of absolute risk of lung cancer mortality in former smokers," Journal of the National Cancer Institute, vol. 85, no. 6, pp. 457464, 1993.

[3] P. N. Lee, J. S. Fry, and J. S. Hamling, "Using the negative exponential distribution to quantitatively review the evidence on how rapidly the excess risk of ischaemic heart disease declines following quitting smoking," Regulatory Toxicology and Pharmacology, vol. 64, no. 1, pp. 51-67, 2012.

[4] J. S. Fry, P. N. Lee, B. A. Forey, and K. J. Coombs, "How rapidly does the excess risk of lung cancer decline following quitting smoking? A quantitative review using the negative exponential model," Regulatory Toxicology and Pharmacology, vol. 67, no. 1, pp. 13-26, 2013.

[5] P. N. Lee, J. S. Fry, and B. A. Forey, "Estimating the decline in excess risk of chronic obstructive pulmonary disease following quitting smoking - a systematic review based on the negative exponential model," Regulatory Toxicology and Pharmacology, vol. 68, no. 2, pp. 231-239, 2014.

[6] P. N. Lee, J. S. Fry, and A. J. Thornton, "Estimating the decline in excess risk of cerebrovascular disease following quitting smoking - a systematic review based on the negative exponential model," Regulatory Toxicology and Pharmacology, vol. 68 , no. 1, pp. 85-95, 2014.

[7] P. N. Lee, "The effect of reducing the number of cigarettes smoked on risk of lung cancer, COPD, cardiovascular disease and $\mathrm{FEV}_{1}$ - a review," Regulatory Toxicology and Pharmacology, vol. 67, no. 3, pp. 372-381, 2013.

[8] R. Weitkunat, P. N. Lee, G. Baker, Z. Sponsiello-Wang, A. M. González-Zuloeta Ladd, and F. Lüdicke, "A novel approach to assess the population health impact of introducing a modified risk tobacco product," Regulatory Toxicology and Pharmacology, vol. 72, no. 1, pp. 87-93, 2015.

[9] J. Hamling, P. Lee, R. Weitkunat, and M. Ambühl, "Facilitating meta-analyses by deriving relative effect and precision estimates for alternative comparisons from a set of estimates presented by exposure level or disease category," Statistics in Medicine, vol. 27, no. 7, pp. 954-970, 2008. 
[10] M. R. Alderson, P. N. Lee, and R. Wang, "Risks of lung cancer, chronic bronchitis, ischaemic heart disease, and stroke in relation to type of cigarette smoked," Journal of Epidemiology and Community Health, vol. 39, no. 4, pp. 286-293, 1985.

[11] C. Bosetti, E. Negri, A. Tavani, L. Santoro, and C. La Vecchia, "Smoking and acute myocardial infarction among women and men: a case-control study in Italy," Preventive Medicine, vol. 29, no. 5, pp. 343-348, 1999.

[12] J. L. Tang, D. G. Cook, and A. G. Shaper, "Giving up smoking: how rapidly does the excess risk of ischaemic heart disease disappear?" Journal of Smoking-Related Disorders, vol. 3, pp. 203-215, 1992.

[13] R. Cederlöf, L. Friberg, Z. Hrubec, and U. Lorich, The Relationship of Smoking and Some Social Covariables to Mortality and Cancer Morbidity. A Ten Year Follow-Up in a Probability Sample of 55,000 Swedish Subjects Age 18-69, part 1-2, Department of Environmental Hygiene, Karolinska Institute, Stockholm, Sweden, 1975.

[14] E. C. Hammond and L. Garfinkel, "Coronary heart disease, stroke, and aortic aneurysm. Factors in the etiology," Archives of Environmental Health, vol. 19, no. 2, pp. 167-182, 1969.

[15] US Surgeon General, The Health Benefits of Smoking Cessation. A Report of the SurgeonGeneral, DHHS Publication no. (CDC) 90-8416, US Department of Health and Human Services, Public Health Service, Centers for Disease Control, Center for Chronic Disease Prevention and Health Promotion, Office on Smoking and Health, Rockville, Md, USA, 1990, http://www.surgeongeneral.gov/library/reports/index.html.

[16] A. J. Dobson, H. M. Alexander, R. F. Heller, and D. M. Lloyd, "How soon after quitting smoking does risk of heart attack decline?” Journal of Clinical Epidemiology, vol. 44, no. 11, pp. 1247-1253, 1991.

[17] R. Doll and R. Peto, "Mortality in relation to smoking: 20 years' observations on male British doctors," British Medical Journal, vol. 2, no. 6051, pp. 1525-1536, 1976.

[18] E. C. Hammond and D. Horn, "Smoking and death ratesreport on forty-four months of follow-up of 187,783 men II. Death rates by cause," The Journal of the American Medical Association, vol. 166, no. 11, pp. 1294-1308, 1958.

[19] T. Hirayama, Life-Style and Mortality: A Large Scale Census Based Cohort Study in Japan, vol. 6, Karger, Basel, Switzerland, 1990.

[20] K. Honjo, H. Iso, S. Tsugane et al., "The effects of smoking and smoking cessation on mortality from cardiovascular disease among Japanese: pooled analysis of three large-scale cohort studies in Japan," Tobacco Control, vol. 19, no. 1, pp. 50-57, 2010.

[21] H. A. Kahn, "The Dorn study of smoking and mortality among U.S. veterans: report on eight and one-half years of observation," in Epidemiological Approaches to the Study of Cancer and Other Chronic Diseases, W. Haenszel, Ed., vol. 19 of National Cancer Institute Monograph, pp. 1-125, U.S. Department of Health, Education, and Welfare. Public Health Service National Cancer Institute, Bethesda, Md, USA, 1966.

[22] K. K. Teo, S. Ounpuu, S. Hawken et al., “Tobacco use and risk of myocardial infarction in 52 countries in the INTERHEART study: a case-control study," The Lancet, vol. 368, no. 9536, pp. 647-658, 2006

[23] G. D. Friedman, I. Tekawa, M. Sadler, and S. Sidney, "Smoking and mortality: the Kaiser permanente experience," in Changes in Cigarette-Related Disease Risks and Their Implications for Prevention and Control, D. R. Shopland, D. M. Burns, L. Garfinkel, and J. M. Samet, Eds., Smoking and Tobacco Control.
Monograph no. 8. NIH Publication no. 97-4213, pp. 477-499, US Department of Health and Human Services, National Institutes of Health, National Cancer Institute, Rockville, Md, USA, 1997, http://cancercontrol.cancer.gov/tcrb/monographs/8/m8_6.pdf.

[24] E. Negri, C. La Vecchia, B. D’Avanzo, A. Nobili, and R. G. La Malfa, "Acute myocardial infarction: association with time since stopping smoking in Italy," Journal of Epidemiology and Community Health, vol. 48, no. 2, pp. 129-133, 1994.

[25] S. A. Kenfield, M. J. Stampfer, B. A. Rosner, and G. A. Colditz, "Smoking and smoking cessation in relation to mortality in women," Journal of the American Medical Association, vol. 299, no. 17, pp. 2037-2047, 2008.

[26] A. Paganini-Hill and G. Hsu, "Smoking and mortality among residents of a California retirement community," American Journal of Public Health, vol. 84, no. 6, pp. 992-995, 1994.

[27] L. Rosenberg, J. R. Palmer, and S. Shapiro, "Decline in the risk of myocardial infarction among women who stop smoking," The New England Journal of Medicine, vol. 322, no. 4, pp. 213-217, 1990.

[28] L. Rosenberg, D. W. Kaufman, S. P. Helmrich, and S. Shapiro, "The risk of myocardial infarction after quitting smoking in men under 55 years of age," The New England Journal of Medicine, vol. 313, no. 24, pp. 1511-1514, 1985.

[29] A. Tavani, M. Bertuzzi, E. Negri, L. Sorbara, and C. La Vecchia, "Alcohol, smoking, coffee and risk of non-fatal acute myocardial infarction in Italy," European Journal of Epidemiology, vol. 17, no. 12, pp. 1131-1137, 2002.

[30] A. Tverdal, D. Thelle, I. Stensvold, P. Leren, and K. Bjartveit, "Mortality in relation to smoking history: 13 years' follow-up of 68,000 Norwegian men and women 35-49 years," Journal of Clinical Epidemiology, vol. 46, no. 5, pp. 475-487, 1993.

[31] C. P. Wen, T. Y. Cheng, C.-L. Lin et al., "The health benefits of smoking cessation for adult smokers and for pregnant women in Taiwan," Tobacco Control, vol. 14, supplement 1, pp. i56-i61, 2005.

[32] Y. Ben-Shlomo, G. D. Smith, M. J. Shipley, and M. G. Marmot, "What determines mortality risk in male former cigarette smokers?" American Journal of Public Health, vol. 84, no. 8, pp. 1235-1242, 1994.

[33] M. R. Alderson, P. N. Lee, and R. Wang, "Risk of lung cancer, chronic bronchitis, ischaemic heart disease, and stroke in relation to type of cigarette smoked, passive smoking and other factors," Tech. Rep., P N Lee Statistics and Computing, Sutton, UK, 1986, http://www.pnlee.co.uk/Reports.htm.

[34] G. Dean, P. N. Lee, G. F. Todd, and A. J. Wicken, "Report on a second retrospective mortality study in North-East EnglandPart I. Factors related to mortality from lung cancer, bronchitis, heart disease and stroke in Cleveland County, with particular emphasis on the relative risks associated with smoking filter and plain cigarettes," Research Paper 14, Tobacco Research Council, London, UK, 1977.

[35] F. Forastiére, J. Balmes, M. Scarinci, and I. B. Tager, "Occupation, asthma, and chronic respiratory symptoms in a community sample of older women," American Journal of Respiratory and Critical Care Medicine, vol. 157, no. 6, pp. 1864-1870, 1998.

[36] E. Huhti and J. Ikkala, "A 10-year follow-up study of respiratory symptoms and ventilatory function in a middle-aged rural population," European Journal of Respiratory Diseases, vol. 61, no. 1, pp. 33-45, 1980.

[37] D. R. Jacobs Jr., H. Adachi, I. Mulder et al., "Cigarette smoking and mortality risk. Twenty-five-year follow-up of the Seven 
Countries Study," Archives of Internal Medicine, vol. 159, no. 7, pp. 733-740, 1999.

[38] K. Jamrozik, D. McLaughlin, K. McCaul et al., "Women who smoke like men die like men who smoke: findings from two Australian cohort studies," Tobacco Control, vol. 20, no. 4, pp. 258-265, 2011.

[39] E. Rogot and J. L. Murray, "Smoking and causes of death among U.S. veterans: 16 years of observation," Public Health Reports, vol. 95, no. 3, pp. 213-222, 1980.

[40] M. Krzyzanowski, W. Jedrychowski, and M. Wysocki, "Factors associated with the change in ventilatory function and the development of chronic obstructive pulmonary disease in a 13year follow-up of the Cracow study. Risk of chronic obstructive pulmonary disease," The American Review of Respiratory Disease, vol. 134, no. 5, pp. 1011-1019, 1986.

[41] D. M. Mannino, A. S. Buist, T. L. Petty, P. L. Enright, and S. C. Redd, "Lung function and mortality in the United States: data from the First National Health and Nutrition Examination Survey follow up study," Thorax, vol. 58, no. 5, pp. 388-393, 2003.

[42] A. Shankar, J.-M. Yuan, W.-P. Koh, H.-P. Lee, and M. C. Yu, "Morbidity and mortality in relation to smoking among women and men of Chinese ethnicity: the Singapore Chinese Health Study," European Journal of Cancer, vol. 44, no. 1, pp. 100-109, 2008.

[43] C. S. Anderson, V. Feigin, D. Bennett, R.-B. Lin, G. Hankey, and K. Jamrozik, "Active and passive smoking and the risk of subarachnoid hemorrhage - an international population-based case-control study," Stroke, vol. 35, no. 3, pp. 633-637, 2004.

[44] S. G. Wannamethee, A. G. Shaper, P. H. Whincup, and M. Walker, "Smoking cessation and the risk of stroke in middleaged men," The Journal of the American Medical Association, vol. 274, no. 2, pp. 155-160, 1995.

[45] D. M. Burns, T. G. Shanks, W. Choi, M. J. Thun, C. W. Heath Jr., and L. Garfinkel, "The American Cancer Society cancer prevention study I: 12-year follow-up of 1 million men and women," in Changes in Cigarette-Related Disease Risks and Their Implications for Prevention and Control, D. R. Shopland, D. M. Burns, L. Garfinkel, and J. M. Samet, Eds., Smoking and Tobacco Control. Monograph no. 8. NIH Publication no. 97-4213, pp. 113-304, US Department of Health and Human Services, National Institutes of Health, National Cancer Institute, Rockville, Md, USA, 1997, http://cancercontrol.cancer.gov/tcrb/monographs/8/m8_3.pdf.

[46] G. A. Donnan, J. J. McNeil, M. A. Adena, A. E. Doyle, H. O'Malley, and G. C. Neill, "Smoking as a risk factor for cerebral ischaemia," The Lancet, vol. 334, no. 8664, pp. 643-647, 1989.

[47] T. Kondo, S. Osugi, K. Shimokata et al., "Smoking and smoking cessation in relation to all-cause mortality and cardiovascular events in 25,464 healthy male Japanese workers," Circulation Journal, vol. 75, no. 12, pp. 2885-2892, 2011.

[48] W. T. Longstreth Jr., L. M. Nelson, T. D. Koepsell, and G. van Belle, "Cigarette smoking, alcohol use, and subarachnoid hemorrhage," Stroke, vol. 23, no. 9, pp. 1242-1249, 1992.

[49] K. E. Anderson, C. Woo, J. E. Olson et al., "Association of family history of cervical, ovarian, and uterine cancer with histological categories of lung cancer: the Iowa Women's Health Study," Cancer Epidemiology, Biomarkers \& Prevention, vol. 6, no. 6, pp. 401-405, 1997.

[50] I. D. J. Bross and R. Gibson, "Risks of lung cancer in smokers who switch to filter cigarettes," American Journal of Public Health, vol. 58, no. 8, pp. 1396-1403, 1968.

[51] S. J. London, A. K. Daly, J. Cooper, W. C. Navidi, C. L. Carpenter, and J. R. Idle, "Polymorphism of glutathione S-transferase M1 and lung cancer risk among African-Americans and Caucasians in Los Angeles County, California," Journal of the National Cancer Institute, vol. 87, no. 16, pp. 1246-1253, 1995.

[52] P.-H. Chyou, A. M. Y. Nomura, G. N. Stemmermann, and I. Kato, "Lung cancer: a prospective study of smoking, occupation, and nutrient intake," Archives of Environmental Health, vol. 48 , no. 2 , pp. 69-72, 1993.

[53] M. J. Thun, C. Day-Lally, D. G. Myers, E. E. Calle, D. Flanders, and B.-P. Zhu, "Age and the exposure-response relationships between cigarette smoking and premature death in Cancer Prevention Study II," in Changes in Cigarette-Related Disease Risks and Their Implications for Prevention and Control, D. R. Shopland, D. M. Burns, L. Garfinkel, and J. M. Samet, Eds., Smoking and Tobacco Control Monograph No. 8, NIH Pub. No. 97-4213, pp. 383-475, US Department of Health and Human Services, National Institutes of Health, National Cancer Institute, Rockville, Md, USA, 1997, http://cancercontrol.cancer .gov/brp/tcrb/monographs/8/m8_5.pdf.

[54] J. F. Dorgan, R. G. Ziegler, J. B. Schoenberg et al., "Race and sex differences in associations of vegetables, fruits, and carotenoids with lung cancer risk in New Jersey (United States)," Cancer Causes and Control, vol. 4, no. 3, pp. 273-281, 1993.

[55] J. K. McLaughlin, Z. Hrubec, W. J. Blot, and J. F. Fraumeni Jr., "Smoking and cancer mortality among U.S. Veterans: a 26-year follow-up," International Journal of Cancer, vol. 60, no. 2, pp. 190-193, 1995.

[56] E. Garshick, M. B. Schenker, A. Muñoz et al., "A case-control study of lung cancer and diesel exhaust exposure in railroad workers," American Review of Respiratory Disease, vol. 135, no. 6, pp. 1242-1248, 1987.

[57] S. Graham and M. L. Levin, "Smoking withdrawal in the reduction of risk of lung cancer," Cancer, vol. 27, no. 4, pp. 865871, 1971.

[58] E. C. Hammond, I. J. Selikoff, and H. Seidman, "Asbestos exposure, cigarette smoking and death rates," Annals of the New York Academy of Sciences, vol. 330, pp. 473-490, 1979.

[59] H. A. Risch, G. R. Howe, M. Jain, J. D. Burch, E. J. Holowaty, and A. B. Miller, "Are female smokers at higher risk for lung cancer than male smokers? A case-control analysis by histologic type," The American Journal of Epidemiology, vol. 138, no. 5, pp. 281293, 1993.

[60] S. A. Khuder, H. H. Dayal, A. B. Mutgi, J. C. Willey, and G. Dayal, "Effect of cigarette smoking on major histological types of lung cancer in men," Lung Cancer, vol. 22, no. 1, pp. 15-21, 1998.

[61] J. Siemiatycki, D. Krewski, E. Franco, and M. Kaiserman, "Associations between cigarette smoking and each of 21 types of cancer: a multi-site case-control study," International Journal of Epidemiology, vol. 24, no. 3, pp. 504-514, 1995.

[62] F. E. Speizer, G. A. Colditz, D. J. Hunter, B. Rosner, and C. Hennekens, "Prospective study of smoking, antioxidant intake, and lung cancer in middle-aged women (USA)," Cancer Causes and Control, vol. 10, no. 5, pp. 475-482, 1999.

[63] E. L. Wynder, K. Mabuchi, and E. J. Beattie Jr., "The epidemiology of lung cancer. Recent trends," The Journal of the American Medical Association, vol. 213, no. 13, pp. 2221-2228, 1970.

[64] R. E. Harris, E. A. Zang, J. I. Anderson, and E. L. Wynder, "Race and sex differences in lung cancer risk associated with cigarette smoking," International Journal of Epidemiology, vol. 22, no. 4, pp. 592-599, 1993. 
[65] L.-C. Yong, C. C. Brown, A. Schatzkin et al., "Intake of vitamins E, C, and A and risk of lung cancer. The NHANES I Epidemiologic Followup Study," The American Journal of Epidemiology, vol. 146, no. 3, pp. 231-243, 1997.

[66] R. W. Field, D. J. Steck, B. J. Smith et al., "Residential radon gas exposure and lung cancer. The Iowa Radon Lung Cancer Study," The American Journal of Epidemiology, vol. 151, no. 11, pp. 1091$1102,2000$.

[67] Y.-C. A. Lee, H. Morgenstern, S. Greenland et al., "A casecontrol study of the association of the polymorphisms and haplotypes of DNA ligase I with lung and upper-aerodigestivetract cancers," International Journal of Cancer, vol. 122, no. 7, pp. 1630-1638, 2008.

[68] M. F. Leitzmann, C. Koebnick, C. C. Abnet et al., "Prospective study of physical activity and lung cancer by histologic type in current, former, and never smokers," American Journal of Epidemiology, vol. 169, no. 5, pp. 542-553, 2009.

[69] Y. Mao, J. Hu, A.-M. Ugnat, R. Semenciw, and S. Fincham, "Socioeconomic status and lung cancer risk in Canada," International Journal of Epidemiology, vol. 30, no. 4, pp. 809-817, 2001.

[70] A. V. Ramanakumar, M.-E. Parent, and J. Siemiatycki, "Risk of lung cancer from residential heating and cooking fuels in Montreal, Canada," American Journal of Epidemiology, vol. 165, no. 6, pp. 634-642, 2007.

[71] J. A. Satia, A. Littman, C. G. Slatore, J. A. Galanko, and E. White, "Long-term use of $\beta$-carotene, retinol, lycopene, and lutein supplements and lung cancer risk: results from the vitamins and lifestyle (vital) study," The American Journal of Epidemiology, vol. 169, no. 7, pp. 815-828, 2009.

[72] S. D. Stellman, T. Takezaki, L. Wang et al., "Smoking and lung cancer risk in American and Japanese men: an international case-control study," Cancer Epidemiology Biomarkers and Prevention, vol. 10, no. 11, pp. 1193-1199, 2001.

[73] R. E. Thompson, D. F. Nelson, J. H. Popkin, and Z. Popkin, "Case-control study of lung cancer risk from residential radon exposure in Worcester County, Massachusetts," Health Physics, vol. 94, no. 3, pp. 228-241, 2008.

[74] S. D. Stellman, Y. Chen, J. E. Muscat et al., "Lung cancer risk in white and black Americans," Annals of Epidemiology, vol. 13, no. 4, pp. 294-302, 2003.

[75] B. Zhang, R. Ferrence, J. Cohen et al., "Smoking cessation and lung cancer mortality in a cohort of middle-aged Canadian women," Annals of Epidemiology, vol. 15, no. 4, pp. 302-309, 2005.

[76] A. M. D’Amelio Jr., A. Cassidy, K. Asomaning et al., "Comparison of discriminatory power and accuracy of three lung cancer risk models," British Journal of Cancer, vol. 103, no. 3, pp. 423429, 2010.

[77] L. Armadans-Gil, J. Vaqué-Rafart, J. Rosselló, M. Olona, and M. Alsedà, "Cigarette smoking and male lung cancer risk with special regard to type of tobacco," International Journal of Epidemiology, vol. 28, no. 4, pp. 614-619, 1999.

[78] F. Barbone, M. Bovenzi, F. Cavallieri, and G. Stanta, "Cigarette smoking and histologic type of lung cancer in men," Chest, vol. 112, no. 6, pp. 1474-1479, 1997.

[79] H. Becher, K.-H. Jöckel, J. Timm, H.-E. Wichmann, and K. Drescher, "Smoking cessation and nonsmoking intervals: effect of different smoking patterns on lung cancer risk," Cancer Causes and Control, vol. 2, no. 6, pp. 381-387, 1991.

[80] L. A. Damber and L.-G. Larsson, "Smoking and lung cancer with special regard to type of smoking and type of cancer.
A case-control study in north Sweden," British Journal of Cancer, vol. 53, no. 5, pp. 673-681, 1986.

[81] R. Doll and A. B. Hill, "A study of the aetiology of carcinoma of the lung," The British Medical Journal, vol. 2, no. 4797, pp. 12711286, 1952.

[82] R. Doll, R. Peto, K. Wheatley, R. Gray, and I. Sutherland, "Mortality in relation to smoking: 40 years' observations on male British doctors," British Medical Journal, vol. 309, no. 6959, pp. 901-911, 1994.

[83] J. H. Lubin, W. J. Blot, F. Berrino et al., "Patterns of lung cancer risk according to type of cigarette smoked," International Journal of Cancer, vol. 33, no. 5, pp. 569-576, 1984.

[84] C. Svensson, G. Pershagen, and J. Klominek, "Smoking and passive smoking in relation to lung cancer in women," Acta Oncologica, vol. 28, no. 5, pp. 623-629, 1989.

[85] H. Baysson, M. Tirmarche, G. Tymen et al., "Indoor radon and lung cancer in France," Epidemiology, vol. 15, no. 6, pp. 709-716, 2004.

[86] I. Brüske-Hohlfeld, A. S. Rosario, G. Wölke et al., "Lung cancer risk among former uranium miners of the WISMUT Company in Germany," Health Physics, vol. 90, no. 3, pp. 208-216, 2006.

[87] M. Caicoya and J. A. Mirón, "Cáncer de pulmón y tabaco en Asturias. Un estudio de casos y controles," Gaceta Sanitaria, vol. 17, pp. 226-230, 2003.

[88] A. B. Miller, H.-P. Altenburg, B. Bueno-De-Mesquita et al., "Fruits and vegetables and lung cancer: findings from the European prospective investigation into cancer and nutrition," International Journal of Cancer, vol. 108, no. 2, pp. 269-276, 2004.

[89] L. Simonato, A. Agudo, W. Ahrens et al., "Lung cancer and cigarette smoking in Europe: an update of risk estimates and an assessment of inter-country heterogeneity," International Journal of Cancer, vol. 91, no. 6, pp. 876-887, 2001.

[90] A. Kubik, P. Zatloukal, L. Tomasek et al., "A case-control study of lifestyle and lung cancer associations by histological types," Neoplasma, vol. 55, no. 3, pp. 192-199, 2008.

[91] J. H. Olsen, S. Friis, A. H. Poulsen et al., "Use of NSAIDs, smoking and lung cancer risk," British Journal of Cancer, vol. 98, no. 1, pp. 232-237, 2008.

[92] A. Papadopoulos, F. Guida, S. Cénée et al., "Cigarette smoking and lung cancer in women: results of the French ICARE casecontrol study," Lung Cancer, vol. 74, no. 3, pp. 369-377, 2011.

[93] R. Petrauskaitè, G. Pershagen, and R. Gurevičius, "Lung cancer near an industrial site in Lithuania with major emissions of airway irritants," International Journal of Cancer, vol. 99, no. 1, pp. 106-111, 2002.

[94] M. Rotunno, K. Yu, J. H. Lubin et al., "Phase I metabolic genes and risk of lung cancer: multiple polymorphisms and mRNA expression," PLoS ONE, vol. 4, no. 5, Article ID e5652, 2009.

[95] A. Ruano-Ravina, A. Figueiras, A. Montes-Martínez, and J. M. Barros-Dios, "Dose-response relationship between tobacco and lung cancer: new findings," European Journal of Cancer Prevention, vol. 12, no. 4, pp. 257-263, 2003.

[96] R. Rylander and G. Axelsson, "Lung cancer risks in relation to vegetable and fruit consumption and smoking," International Journal of Cancer, vol. 118, no. 3, pp. 739-743, 2006.

[97] L. Tomasek, "Interaction of radon and smoking among Czech uranium miners," Radiation Protection Dosimetry, vol. 145, no. 2-3, Article ID ncr048, pp. 238-242, 2011.

[98] S.-Y. Choi, K.-H. Lee, and T.-O. Lee, "A case-control study on risk factors in lung cancer," Korean Journal of Epidemiology, vol. 11, pp. 66-80, 1989. 
[99] E. De Stefani, L. Fierro, P. Correa et al., "Mate drinking and risk of lung cancer in males: a case-control study from Uruguay," Cancer Epidemiology Biomarkers and Prevention, vol. 5, no. 7, pp. 515-519, 1996.

[100] Y.-T. Gao, W. J. Blot, W. Zheng, J. F. Fraumeni, and C.-W. Hsu, "Lung cancer and smoking in Shanghai," International Journal of Epidemiology, vol. 17, no. 2, pp. 277-280, 1988.

[101] C.-M. Gao, K. Tajima, T. Kuroishi, K. Hirose, and M. Inoue, "Protective effects of raw vegetables and fruit against lung cancer among smokers and ex-smokers: a case-control study in the Tokai area of Japan," Japanese Journal of Cancer Research, vol. 84, no. 6, pp. 594-600, 1993.

[102] O. G. Joly, J. L. Lubin, and M. Caraballoso, "Dark tobacco and lung cancer in Cuba," Journal of the National Cancer Institute, vol. 70, no. 6, pp. 1033-1039, 1983.

[103] J. H. Lubin, L. Jun-Yao, X. Xiang-Ghen et al., "Risk of lung cancer among cigarette and pipe smokers in Southern China," International Journal of Cancer, vol. 51, no. 3, pp. 390-395, 1992.

[104] E. Matos, M. Vilensky, P. Boffetta, and M. Kogevinas, "Lung cancer and smoking: a case-control study in Buenos Aires, Argentina," Lung Cancer, vol. 21, no. 3, pp. 155-163, 1998.

[105] S. M. Pezzotto and L. Poletto, "Occupation and histopathology of lung cancer: a case-control study in Rosario, Argentina," The American Journal of Industrial Medicine, vol. 36, no. 4, pp. 437443, 1999.

[106] S. M. Pezzotto, R. Mahuad, M. L. Bay, J. C. Morini, and L. Poletto, "Variation in smoking-related lung cancer risk factors by cell type among men in Argentina: a case-control study," Cancer Causes and Control, vol. 4, no. 3, pp. 231-237, 1993.

[107] T. Sobue, T. Suzuki, I. Fujimoto et al., "Case-control study for lung cancer and cigarette smoking in Osaka, Japan: comparison with the results from Western Europe," Japanese Journal of Cancer Research, vol. 85, no. 5, pp. 464-473, 1994.

[108] I. Suzuki, G. S. Hamada, M. M. Zamboni, P. B. Cordeiro, S. Watanabe, and S. Tsugane, "Risk factors for lung cancer in Rio de Janeiro, Brazil: a case-control study," Lung Cancer, vol. 11, no. 3-4, pp. 179-190, 1994.

[109] K. Wakai, Y. Ohno, K. Genka et al., "Smoking habits, local brand cigarettes and lung cancer risk in okinawa, Japan," Journal of Epidemiology, vol. 7, no. 2, pp. 99-105, 1997.

[110] J. S. Wang, "A case-control interview study on risk factors of lung cancer in the city of Taiyuan," Zhonghua Liu Xing Bing Xue Za Zhi, vol. 6, no. 3, pp. 162-165, 1985.

[111] Y. Bhurgri, E. Decullier, A. Bhurgri et al., "A case-control study of lung cancer in Karachi, Pakistan [letter]," International Journal of Cancer, vol. 98, pp. 952-955, 2002.

[112] E. de Stefani, P. Brennan, A. Ronco et al., "Food groups and risk of lung cancer in Uruguay," Lung Cancer, vol. 38, no. 1, pp. 1-7, 2002.

[113] E. de Stefani, A. L. Ronco, P. Boffetta, H. Deneo-Pellegrini, G. Acosta, and M. Mendilaharsu, "Meat consumption, meat cooking and risk of lung cancer among Uruguayan men," Asian Pacific Journal of Cancer Prevention, vol. 11, no. 6, pp. 1713-1717, 2010.

[114] F. Franco-Marina, J. Villalba Caloca, A. Corcho-Berdugo et al., "Role of active and passive smoking on lung cancer etiology in Mexico City," Salud Publica de Mexico, vol. 48, supplement 1, pp. S75-S82, 2006.

[115] V. Gajalakshmi, R. J. Hung, A. Mathew, C. Varghese, P. Brennan, and P. Boffetta, "Tobacco smoking and chewing, alcohol drinking and lung cancer risk among men in Southern India," International Journal of Cancer, vol. 107, no. 3, pp. 441-447, 2003.
[116] C.-H. Lee, Y.-C. Ko, L. S.-C. Cheng et al., "The heterogeneity in risk factors of lung cancer and the difference of histologic distribution between genders in Taiwan," Cancer Causes and Control, vol. 12, no. 4, pp. 289-300, 2001.

[117] Y. Osaki, M. Okamoto, A. Kaetsu, T. Kishimoto, and A. Suyama, "Retrospective cohort study of smoking and lung cancer incidence in rural prefecture, Japan," Environmental Health and Preventive Medicine, vol. 12, no. 4, pp. 178-182, 2007.

[118] S. K. Park, L. Y. Cho, J. J. Yang et al., "Lung cancer risk and cigarette smoking, lung tuberculosis according to histologic type and gender in a population based case-control study," Lung Cancer, vol. 68, no. 1, pp. 20-26, 2010.

[119] A. Reid, N. H. De Klerk, G. L. Ambrosini, G. Berry, and A. W. Musk, "The risk of lung cancer with increasing time since ceasing exposure to asbestos and quitting smoking," Occupational and Environmental Medicine, vol. 63, no. 8, pp. 509-512, 2006.

[120] L. A. Tse, I. T.-S. Yu, H. Qiu et al., "Lung cancer decreased sharply in first 5 years after smoking cessation in Chinese men," Journal of Thoracic Oncology, vol. 6, no. 10, pp. 1670-1676, 2011.

[121] K. Wakai, T. Marugame, S. Kuriyama et al., "Decrease in risk of lung cancer death in Japanese men after smoking cessation by age at quitting: pooled analysis of three large-scale cohort studies," Cancer Science, vol. 98, no. 4, pp. 584-589, 2007.

[122] W.-P. Koh, J.-M. Yuan, R. Wang, H.-P. Lee, and M. C. Yu, "Body mass index and smoking-related lung cancer risk in the Singapore Chinese Health Study," British Journal of Cancer, vol. 102, no. 3, pp. 610-614, 2010.

[123] J. S. Fry, P. N. Lee, B. A. Forey, and K. J. Coombs, "Is the shape of the decline in risk following quitting smoking similar for squamous cell carcinoma and adenocarcinoma of the lung? A quantitative review using the negative exponential model," Regulatory Toxicology and Pharmacology, vol. 72, no. 1, pp. 4957, 2015.

[124] US Surgeon General, Smoking and Health. A Report of the Surgeon General, DHEW Publication No. (PHS) 79-50066, US Department of Health, Education, and Welfare, Public Health Service, Rockville, Md, USA, 1979, http://www.surgeongeneral .gov/library/reports/index.html.

[125] National Cancer Institute, Changes in Cigarette-Related Disease Risks and Their Implications for Prevention and Control, Smoking and Tobacco Control. Monograph no. 8. NIH Publication no. 97-4213, US Department of Health and Human Services, National Institutes of Health, National Cancer Institute, Rockville, Md, USA, 1997, edited by: D. R. Shopland, D. M. Burns, L. Garfinkel, J. M. Samet, http://cancercontrol.cancer .gov/Brp/tcrb/monographs/8/index.html.

[126] International Agency for Research on Cancer, IARC Handbooks of Cancer Prevention, Tobacco Control, Volume 11: Reversal of Risk after Quitting Smoking, IARC, Lyon, France, 2007.

[127] R. Doll and R. Peto, "Cigarette smoking and bronchial carcinoma: dose and time relationships among regular smokers and lifelong non-smokers," Journal of Epidemiology and Community Health, vol. 32, no. 4, pp. 303-313, 1978.

[128] J. S. Fry, P. N. Lee, B. A. Forey, and K. J. Coombs, "Dose-response relationship of lung cancer to amount smoked, duration and age starting," World Journal of Meta-Analysis, vol. 1, pp. 57-77, 2013.

[129] Food and Drug Administration, Guidance for Industry: Modified Risk Tobacco Product Applications. Draft Guidance, U.S. Department of Health and Human Services Food and Drug Administration Center for Tobacco Products, 2012. 
[130] B. A. Forey, A. J. Thornton, and P. N. Lee, "Systematic review with meta-analysis of the epidemiological evidence relating smoking to COPD, chronic bronchitis and emphysema," BMC Pulmonary Medicine, vol. 11, article 36, 2011.

[131] US Surgeon General, The Health Consequences of Smoking. A Report of the Surgeon General, US Department of Health and Human Services, Centers for Disease Control and Prevention, National Center for Chronic Disease Prevention and Health Promotion, Office on Smoking and Health, Atlanta, Ga, USA, 2004, http://www.surgeongeneral.gov/library/reports/ index.html.

[132] International Agency for Research on Cancer, Tobacco Smoke and Involuntary Smoking, vol. 83 of IARC Monographs on the Evaluation of Carcinogenic Risks to Humans, IARC, Lyon, France, 2004, http://monographs.iarc.fr/ENG/Monographs/ vol83/mono83.pdf.

[133] P. N. Lee, Studying the Relationship of Smoking to Lung Cancer Using the Multistage Model of Carcinogenesis. A Review, P N Lee Statistics and Computing, Sutton, Surrey, 1995, http://www.pnlee.co.uk/Reports.htm.

[134] P. Armitage and R. Doll, "The age distribution of cancer and a multi-stage theory of carcinogenesis," British Journal of Cancer, vol. 8, pp. 1-12, 1954.

[135] K. S. Crump and R. B. Howe, "The multistage model with a time-dependent dose pattern: applications to carcinogenic risk assessment," Risk Analysis, vol. 4, no. 3, pp. 163-176, 1984.

[136] N. E. Day and C. C. Brown, "Multistage models and primary prevention of cancer," Journal of the National Cancer Institute, vol. 64, no. 4, pp. 977-989, 1980.

[137] N. E. Day, "Epidemiological data and multistage carcinogenesis," in Models, Mechanisms and Etiology of Tumour Promotion, Proceedings of a Symposium Organised by the Hungarian Cancer Society and the IARC Held in Budapest, 16-18 May 83, M. Börzsönyi, N. E. Day, K. Lapis, and H. Yamasaki, Eds., pp. 339357, International Agency for Research on Cancer, 1984.

[138] D. A. Freedman and W. C. Navidi, "Ex-smokers and the multistage model for lung cancer," Epidemiology, vol. 1, no. 1, pp. 21-29, 1990.

[139] M. Gaffney and B. Altshuler, "Examination of the role of cigarette smoke in lung carcinogenesis using multistage models," Journal of the National Cancer Institute, vol. 80, no. 12, pp. 925-931, 1988.

[140] M. Hakama, "Epidemiologic evidence for multi-stage theory of carcinogenesis," International Journal of Cancer, vol. 7, no. 3, pp. 557-564, 1971.

[141] S. Mazumdar, C. K. Redmond, J. P. Costantino, R. N. Patwardhan, and S. Y. J. Zhou, "Recent developments in the multistage modeling of cohort data for carcinogenic risk assessment," Environmental Health Perspectives, vol. 90, pp. 271-277, 1991.

[142] R. Peto, "Epidemiology, multistage models and short-term mutagenicity tests," in Origins of Human Cancer, pp. 1403-1428, Cold Spring Harbor Publications, 1977.

[143] J. B. Swartz, "Use of a multistage model to predict time trends in smoking induced lung cancer," Journal of Epidemiology and Community Health, vol. 46, no. 3, pp. 311-315, 1992.

[144] W. F. Heidenreich, J. Wellmann, P. Jacob, and H. E. Wichmann, "Mechanistic modelling in large case-control studies of lung cancer risk from smoking," Statistics in Medicine, vol. 21, no. 20, pp. 3055-3070, 2002.

[145] W. D. Hazelton, M. S. Clements, and S. H. Moolgavkar, "Multistage carcinogenesis and lung cancer mortality in three cohorts," Cancer Epidemiology Biomarkers \& Prevention, vol. 14, no. 5, pp. 1171-1181, 2005.

[146] H. Schöllnberger, M. Manuguerra, H. Bijwaard et al., "Analysis of epidemiological cohort data on smoking effects and lung cancer with a multi-stage cancer model," Carcinogenesis, vol. 27, no. 7, pp. 1432-1444, 2006.

[147] R. Meza, W. D. Hazelton, G. A. Colditz, and S. H. Moolgavkar, "Analysis of lung cancer incidence in the nurses' health and the health professionals' follow-up studies using a multistage carcinogenesis model," Cancer Causes and Control, vol. 19, no. 3, pp. 317-328, 2008.

[148] N. S. Godtfredsen, E. Prescott, and M. Osler, "Effect of smoking reduction on lung cancer risk," Journal of the American Medical Association, vol. 294, no. 12, pp. 1505-1510, 2005.

[149] A. Tverdal and K. Bjartveit, "Health consequences of reduced daily cigarette consumption," Tobacco Control, vol. 15, no. 6, pp. 472-480, 2006.

[150] Y.-M. Song, J. Sung, and H.-J. Cho, "Reduction and cessation of cigarette smoking and risk of cancer: a cohort study of Korean men," Journal of Clinical Oncology, vol. 26, no. 31, pp. 5101-5106, 2008. 


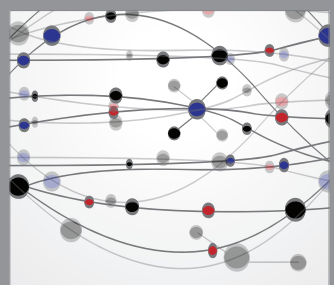

The Scientific World Journal
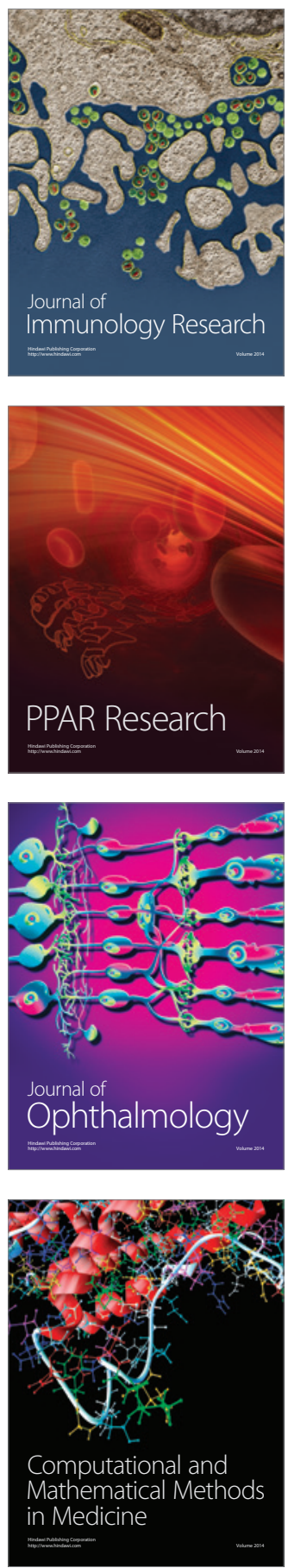

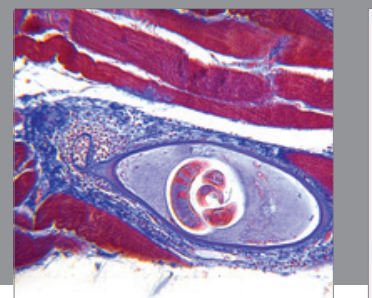

Gastroenterology

Research and Practice
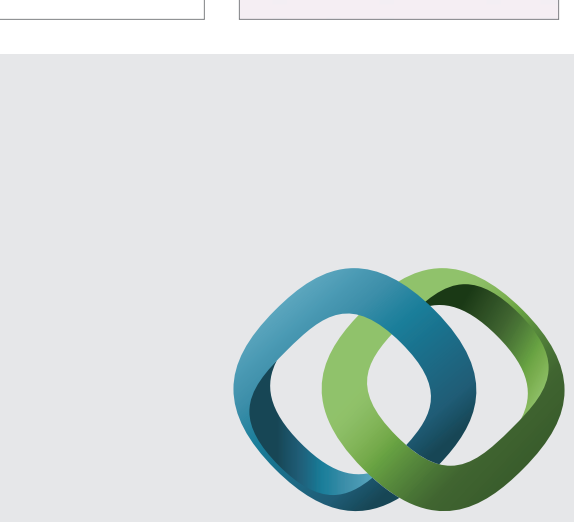

\section{Hindawi}

Submit your manuscripts at

http://www.hindawi.com
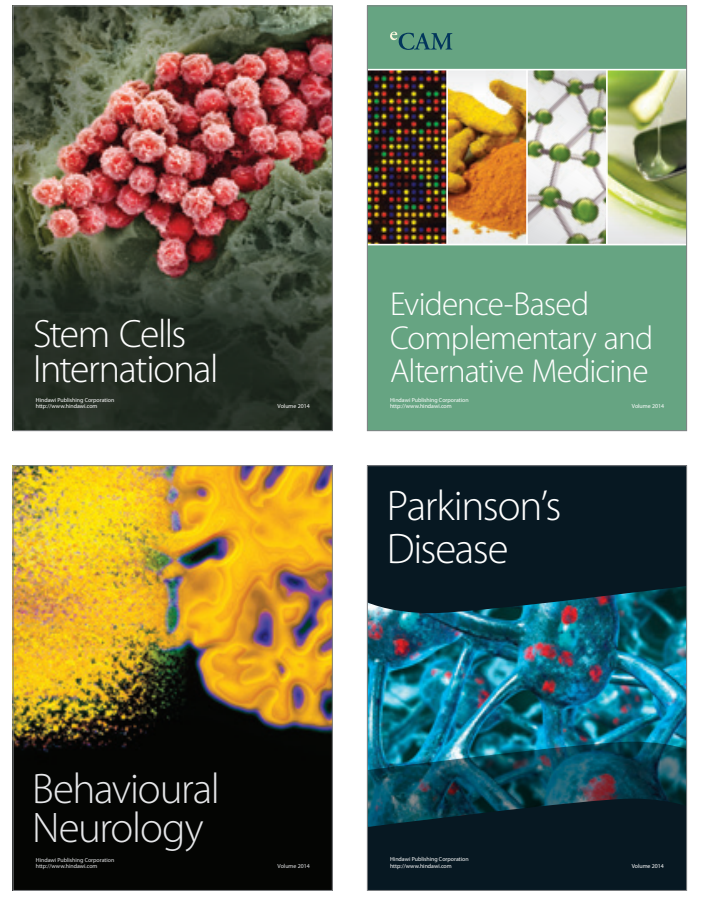
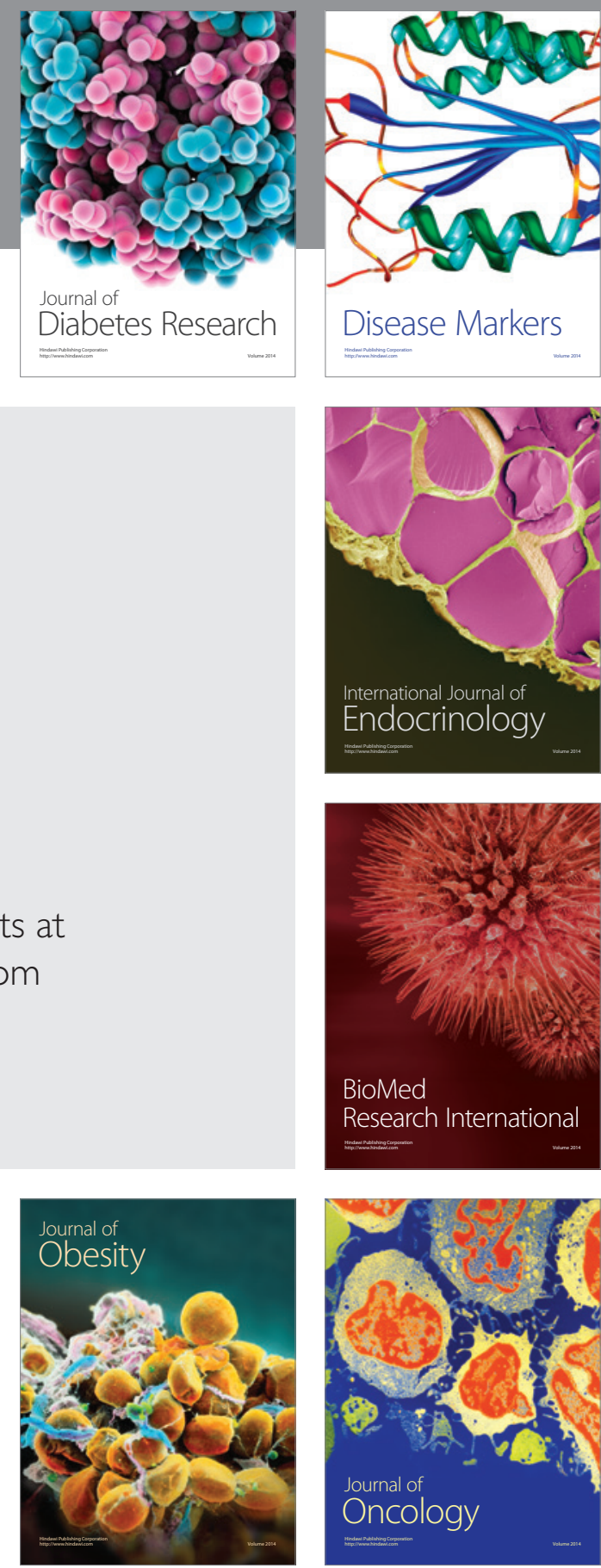

Disease Markers
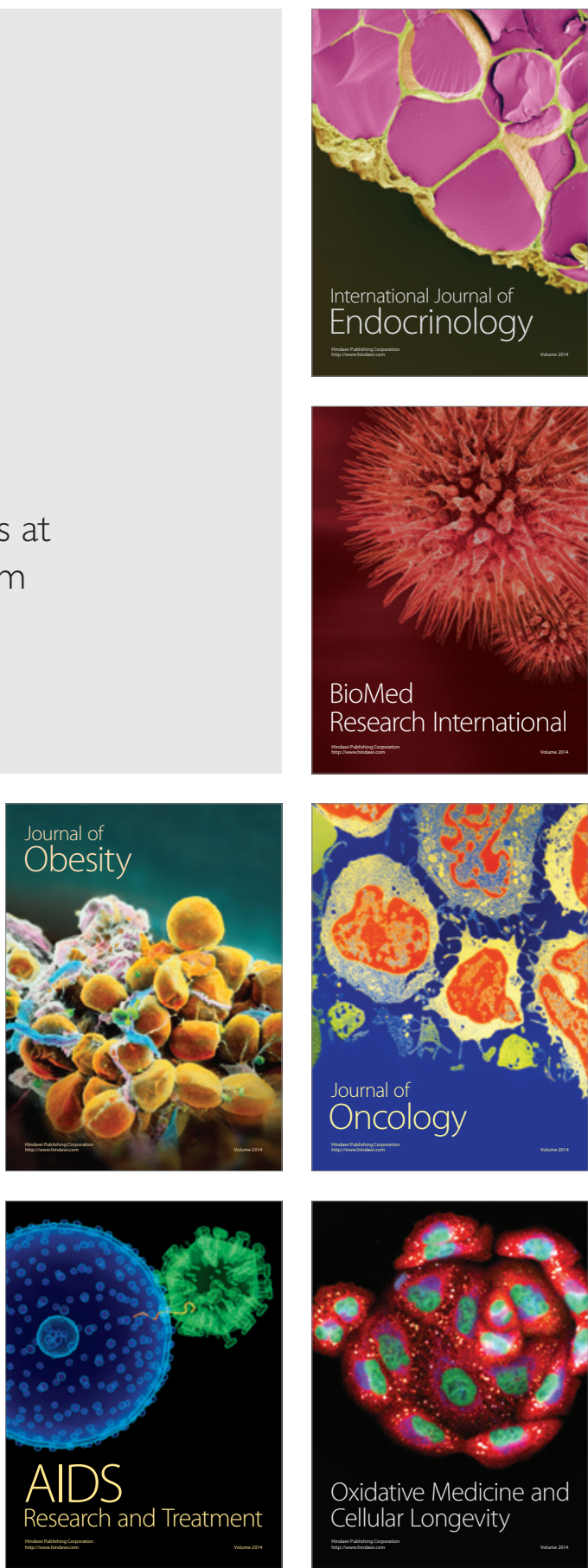